\title{
COVID-19 e o Coração
}

\section{COVID-19 and the Heart}

\author{
Tânia Mara Varejão Strabelli,2 e David Everson Uip ${ }^{3,4,5}$ \\ Faculdade de Medicina Universidade de São Paulo, ${ }^{1}$ São Paulo, SP - Brasil \\ Unidade de Controle de Infecção Hospitalar do Instituto do Coração (InCor HCFMUSP), ${ }^{2}$ São Paulo, SP - Brasil \\ Centro Universitário Saúde $A B C,{ }^{3}$ Santo André, $S P$ - Brasil \\ Centro de Infectologia do Hospital Sírio-Libanês, ${ }^{4}$ São Paulo, SP - Brasil \\ Centro de Contingência do Covid-19 do Estado de São Paulo, ${ }^{5}$ São Paulo, SP - Brasil
}

Estamos vivendo a pandemia do novo coronavírus desde o dia 11 de março de 2020. Inicialmente, em 31 de janeiro de 2020, a Organização Mundial da Saúde (OMS) declarou a infecção pelo novo cornavírus como emergência global e a seguir nomeou a doença de COVID-19. O Grupo de Estudos de Coronavírus do Comitê Internacional de Taxonomia de Vírus propôs que o vírus seja designado de SARS-Cov-2. ${ }^{1}$ O sequenciamento genômico e a análise filogenética indicaram que se trata de um betacoronavírus, do mesmo subgênero da síndrome da insuficiência respiratória aguda grave (SARS), que causou epidemia na China em 2003, e da síndrome respiratória do Médio Oriente (MERS), que causou o mesmo quadro no Oriente Médio em 2012. Há 96,2\% de identidade genética com o betaCoV/bat/Yunnan, vírus isolado de morcegos. A estrutura do gene do receptor de ligação do vírus às células é muito semelhante ao coronavírus da SARS e o vírus parece usar o mesmo receptor enzima 2 de conversão a angiotensiva (ACE2) para entrar na célula.

O quadro clínico da COVID-19 é semelhante ao de outras viroses respiratórias, a saber, febre, tosse geralmente seca, cansaço e, em casos mais graves (5\%), dispneia, sangramento pulmonar, linfopenia grave e insuficiência renal. Em $80 \%$ dos casos, os sintomas são leves. O diagnóstico dos casos sintomáticos deve ser confirmado com a pesquisa do vírus por reação em cadeia da polimerase (PCR) de swab nasal.

O que tem chamado a atenção dos clínicos são as complicações cardíacas desta doença. Num estudo que avaliou 138 pacientes internados por COVID-19, 16,7\% desenvolveram arritmia e 7,2\% apresentaram lesão cardíaca aguda. ${ }^{2}$ Por outro lado, os cardiologistas do Hospital San Raffaele, em Milão, Itália, hospital de referência para complicações cardiovasculares da COVID-19, coletaram

\section{Palavras-chave}

Coronavirus-19/complicações; betaCoV/bat/Yunnan/ complications; Febre; Síndrome Respiratória Aguda Grave; Dispneia; Transtornos Respiratórios; Fatores de Risco; Hipertensão; Diabetes Mellitus.

Correspondência: Tânia Mara Varejão Strabelli •

Av. Marechal Câmara, 160 sala 330. CEP 20020-907, Centro, RJ - Brasil E-mail: tania.s@hc.fm.usp.br

DOI: https://doi.org/10.36660/abc.20200209 enzimas (BNP, troponina, CK-MB) de todos os pacientes para detectar a prevalência de acometimento cardíaco. Em 9 de março, dos 82 pacientes internados, sendo 19 pacientes em UTI, apenas uma paciente de 43 anos foi admitida por dor torácica com alteração do segmento ST e foi diagnosticada com pneumonia. A angiocoronariografia foi normal. ${ }^{3}$

Um grande estudo publicado pelo Centro Chinês de Controle e Prevenção de Doenças, com dados de 44.672 casos confirmados do COVID-19, relatou mortalidade de $2,3 \%$. As comorbidades mais frequentes nos pacientes que evoluíram a óbito foram hipertensão arterial, diabetes mellitus, doença cardiovascular e idade acima de 70 anos . ${ }^{4}$

Outro estudo ${ }^{1}$ publicado a partir da análise retrospectiva do banco de dados de dois hospitais de Wuhan (Jin Yin-tan Hospital e Tongji Hospital) avaliou 150 casos de infecção laboratorialmente confirmada por SARS-CoV-2, dos quais 68 (45\%) evoluíram para óbito. Os critérios utilizados para alta dos pacientes foi estar afebril por pelo menos 3 dias, ter apresentado melhora significativa da função respiratória e ter 2 pesquisas consecutivas negativas do vírus. Houve diferença estatisticamente significante para idade avançada nos pacientes que evoluíram a óbito $(p<0,001)$, porém não houve diferença entre os sexos $(p=0,43)$. Um total de $63 \%$ (43/68) dos pacientes que evoluíram para óbito apresentaram doença de base em comparação a $41 \%$ (34/82) dos que tiveram alta hospitalar ( $p=0,0069)$. Os pacientes com doença cardiovascular associada tiveram maior risco de morte $(p<0,001)$. Houve também maior incidência de infecções secundárias nos pacientes que evoluíram para óbito em comparação aos que tiveram alta $(16 \%$ [11/68] x 1\% [1/82], $p=0,0018)$. A Figura 1 mostra valores mais elevados dos mediadores inflamatórios nos pacientes que evoluíram para óbito, e a Figura 2 resume as causas de óbito.

Outro estudo publicado em The Lancet ${ }^{5}$ identificou valores elevados de interleucina-6 (IL-6), troponina 1 ultrasensível e DHL como achados mais frequentes em pacientes internados que evoluíram para óbito $(\mathrm{n}=54)$ em comparação aos que sobreviveram $(n=137)$ em 2 hospitais de Wuhan, China. Dentre todos os pacientes, 91 (48\%) tinham alguma comorbidade, sendo as mais comuns: hipertensão arterial, 58 pacientes (30\%), diabetes mellitus, 36 pacientes (19\%) e doença coronariana crônica, 15 pacientes (8\%). Entretanto, na análise multivariada de fatores de risco de evolução para óbito, apenas a idade 


\section{Editorial}

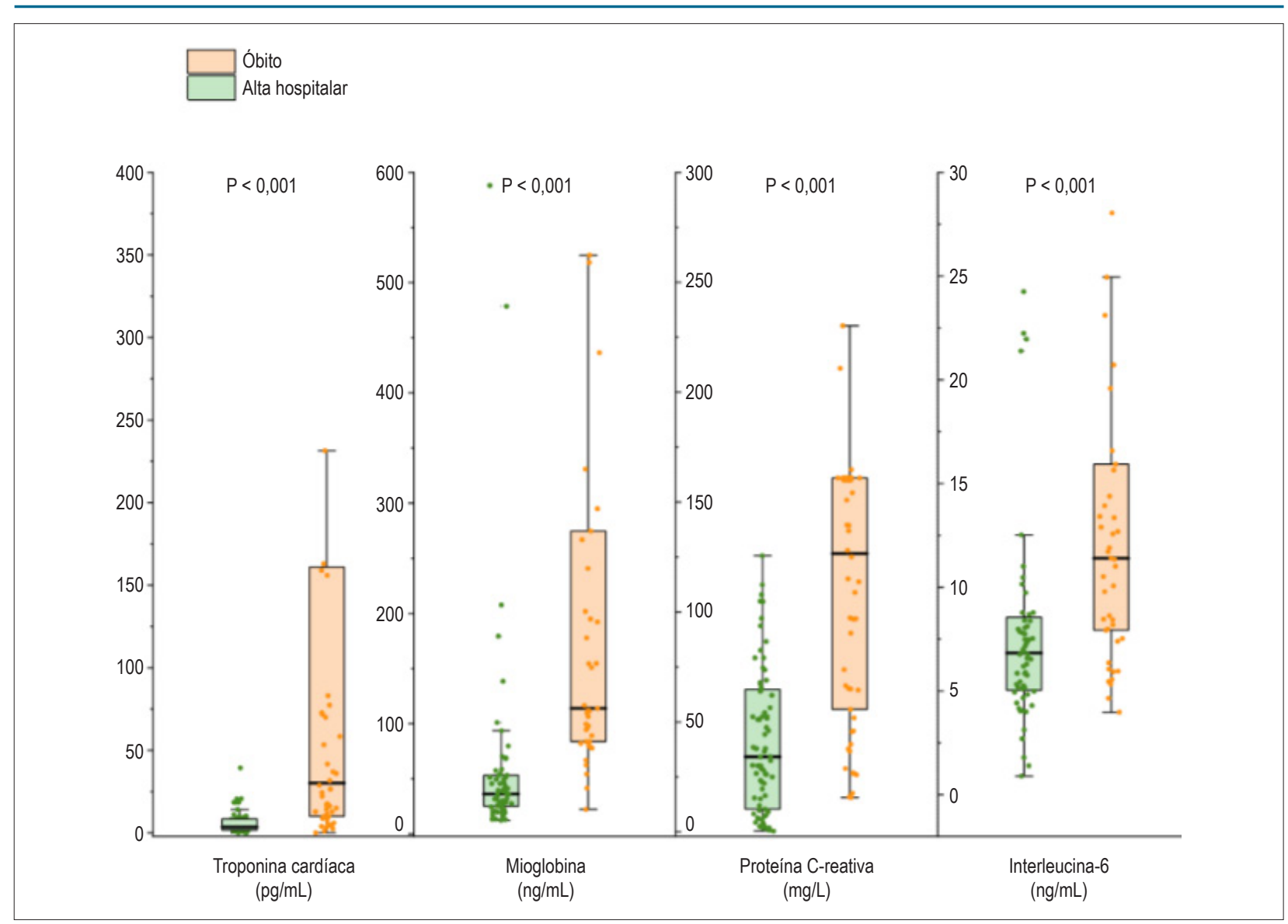

Figura 1 - Principais parâmetros laboratoriais dos de casos de infecção confirmada por COVID-19 de acordo com a evolução. ${ }^{1}$

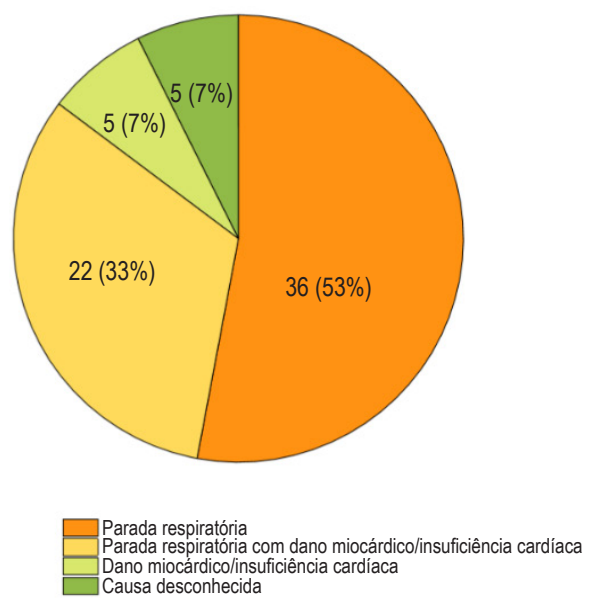

Figura 2 - Resumo das causas de óbito de 68 pacientes confirmados com COVID-19. ${ }^{1}$ 
avançada, escore SOFA elevado e D-dímero acima de $1 \mu \mathrm{g} / \mathrm{l}$ na admissão foram estatisticamente significantes.

Ainda não há evidências de que o uso de inibidores de enzima de conversão da angiotensina (ACE) ou bloqueadores de receptores de angiotensina (ARB) possam afetar a atividade do vírus. O Council on Hypertension of the European Society of Cardiology recomenda que médicos e pacientes devam continuar o tratamento anti-hipertensivo usual.

\section{Referências}

1. Ruan Q, Yang K, Wang W, Jiang L, Song J. Clinical predictors of mortality due to COVID-19 based on an analysis of data of 150 patients from Wuhan, China. Intensive Care Medicine, March,2020. https://doi.org/10.1007/ s00134-020-05991-x

2. Wang D, Hu B, Hu C, Zhu F, Liu X,Zhang J, et al. Clinical characteristics of 138 hospitalized patients with 2019 Novel Corononavirus infected pneumonia in Wuhan, China. JAMA.2020,Feb 07. doi:10.1001/ jama2020.1585.[Epub ahead of print]

3. www.tctmd.com/News/covid-19-and-heart-insights-front-lines. [Cited in 2020 March 17].Available from:www.tctmd.com
Outra recomendação fundamental é de que todos sejam vacinados contra influenza, que já iniciou sua atividade sazonal no Brasil e tem, até este momento, maior mortalidade que o COVID-19.

Este é um momento de vigilância, de bom senso e de investigação científica. As sociedades médicas devem se organizar para que sejam feitos protocolos para reconhecer e tratar complicações.

4. Centers for Disease Control and Prevention (CDC). The Novel Coronavirus Pneumonia Emergency Response Epidemiology Team. The epidemiological characteristics of an outbreak of 2019 novel coronavirus diseases (COVID-19)in China. Zhonghua Liu Xing Bing Xue Za Zhi. 2020;41(2):14551. China, 202. China CDC Weekly.2020,2(8):113-122.

5. Zhou F, Yu T, Du R, Fan G, Liu Y,Liu Z, et al. Clinical course and risk factors for mortality of adult inpatients with COVID-19 in Wuhan, China: a retrospective cohort study. Lancet. 2020 March 11. doi: https://doi.org/10.1016/50140-6736(20)30566-3 